\title{
Assessment of the Role of Everolimus Therapy in Patients with Renal Cell Carcinoma Based on Daily Routine and Recent Research Results
}

\author{
Anikó Maráz ${ }^{1}$ (D) András Csejtei ${ }^{2} \cdot$ Judit Kocsis $^{3} \cdot$ Miklós Szúcs $^{4} \cdot$ Zsuzsanna Kahán $^{1}$ • \\ György Bodoky $^{5} \cdot$ Magdolna Dank $^{6}$ • László Mangel $^{7}$ - János Révész ${ }^{8} \cdot$ Zoltán Varga $^{1}$ • \\ Lajos Géczi ${ }^{9}$
}

Received: 10 May 2017 / Accepted: 20 September 2017

(C) Arányi Lajos Foundation 2017

\begin{abstract}
Everolimus is indicated for adults with metastatic renal cell carcinoma (mRCC) after failure of vascular endothelial growth factor receptor-tyrosine kinase inhibitors (TKI). Currently, the therapeutic applicability of EVE has been changing. Multicenter evaluation of efficacy and safety of everolimus in daily routine and definition of patient characteristics with favorable outcome. Data of 165 patients from 9 oncology institutes in Hungary were analyzed retrospectively. Everolimus therapy was used after one TKI in $10 \mathrm{mg}$ starting dose. Physical and laboratory examinations and imaging tests were performed monthly and every 3 months, respectively. Median progression-free survival (PFS) was 5.4 months. Median overall survival (OS) was 16.2 months. PFS and OS results were more favorable in patients with ECOG $0-1\left(p_{P F S}=0.033\right.$, $\left.p_{O S}=0.008\right)$ and after $>9$ months of TKI therapy $\left(p_{P F S}=0.019, p_{O S}=0.045\right)$. Survival was longer in nonanemic patients with ECOG 0-1 than in anemic patients with ECOG 2$3,30.9$ and 7.7 months, respectively $(p=0.029)$. Dose reduction and treatment delay was required in $6.2 \%$ and $8.9 \%$ of patients,
\end{abstract}

The authors are solely responsible for writing the manuscript and the decision to submit the manuscript for publication.

Anikó Maráz

dr.aniko.maraz@gmail.com

1 Department of Oncotherapy, University of Szeged, Korányi fasor 12, Szeged 6720, Hungary

2 Markusovszky Teaching Hospital, Markusovszky str. 5, Szombathely, Hungary

3 Institute of Oncology, University of Debrecen, Nagyerdei krt. 98., Debrecen, Hungary

4 Faculty of Medicine, Department of Urology and Urooncological Centre, Semmelweis University, Üllői str. 78/b, Budapest, Hungary respectively. Common adverse events were exanthema, edema, stomatitis, anemia, and abnormal kidney functions and glucose levels. Results of this study show that everolimus is safe and efficacious in a real-world setting. Everyday practice showed that nonanemic patients with good performance status receiving TKI therapy for $>9$ months are favorable candidates for this treatment. Despite the efficiency of novel, registered drugs, everolimus still plays an important role during and after second-line therapy for $\mathrm{mRCC}$ when availability of modern remedies is limited.

Keywords Metastatic kidney cancer $\cdot$ mTOR inhibitor . Everolimus $\cdot$ Anemia $\cdot \mathrm{ECOG} \cdot \mathrm{RCC}$

\section{Introduction}

Everolimus (Afinitor ${ }^{\circledR}$, Novartis) (EVE), an oral mammalian target of rapamycin (mTOR) inhibitor, has been evaluated in
Department of Oncology, Integrated St. Istvan and St. Laszlo Hospital, Albert Flórián str. 5-7, Budapest, Hungary

6 Faculty of Medicine, 1st Department of Internal Medicine, Division of Oncology, Semmelweis University, Tömő str.25-29, Budapest, Hungary

7 Institute of Oncotherapy, University of Pécs, Édesanyák 17., Pécs, Hungary

8 Institute of Radiotherapy and Clinical Oncology, Borsod County Hospital and University Academic Hospital, Szentpéteri Kapu 72-76, Miskolc, Hungary

$9 \quad$ National Institute of Oncology, Chemotherapy C and Clinical Pharmacology, Ráth György str. 7-9, Budapest, Hungary 
preclinical studies and in numerous clinical trials in the past decade [1]. PI3K/AKT/mTOR is an intracellular signaling pathway in which $\mathrm{mTOR}$ is a protein kinase involved in the regulation of several cellular functions such as proliferation, growth and survival [2]. This mentioned pathway plays a central role in tumorigenesis of renal cell cancers (RCC) [3]. The anti-tumor effect of EVE had been confirmed in the therapy of advanced or metastatic RCC (mRCC), and then neuroendocrine tumors of pancreatic origin, of other gastrointestinal or lung origin, and hormone receptor-positive advanced breast cancers [4-7].

The first registration study of EVE was a phase 3 placebocontrolled study for the treatment of advanced RCC (RECORD1 ), in which the patients' disease has previously progressed on or after sunitinib and/or sorafenib therapy. Progression-free survival (PFS) was significantly longer in patients who received EVE than those who received placebo (4.9 months vs 1.9 months) [4]. The difference between the overall survival (OS) of the two arms was equalized due to crossover after progression (14.8 months with EVE vs 14.4 months with placebo) [8]. The results of the subgroup after failure on one line vascular endothelial growth factor receptor (VEGFR) tyrosine kinase inhibitor (TKI) therapy demonstrated more favorable PFS (5.4 months) [9]. According to the international guidelines (e.g., NCCN, ESMO, EAU), EVE can be used to treat patients with $\mathrm{mRCC}$ whose condition progressed during or after antiVEGFR TKI [10-12].

Currently, the therapeutic administration of EVE has been changing. The results of one new phase 2 and two phase 3 studies have been published in the past two years with respect to $\mathrm{mRCC}$, in which EVE was the comparator of the investigated drugs. The survival rates were more favorable in the immune checkpoint inhibitor nivolumab, TKI cabozantinib, and also in the tri-specific targeted VEGFR-, RET- and fibroblast growth factor receptor (FGFR) inhibitor lenvatinib combined with the EVE arms compared to EVE administered alone [13-16] [Table 1]. According to the recent guidelines, the role of EVE should be amended in the clinical practice [17].
Besides the therapeutic efficiency of novel remedies, the availability of new therapeutic options also influences the survival of oncologic patients. In some economic regions, the financing of new therapies with high cost is limited, so in the everyday practice, the oncologist has to maximize the efficiency of new therapeutic options with the available resources.

Aim of our study was to retrospectively analyze the maximal efficiency and the side-effects of EVE in the everyday practice of different oncology centers. We wished to define patient characteristics which made the therapy more effective.

\section{Patients and Methods}

Patients Everolimus was administered to 165 patients with mRCC between January 2010 and December 2013 in nine Hungarian oncological institutes. The study was performed in accordance with the Hungarian drug law and relevant guidelines of the Hungarian health authorities. The study design was approved by the ethics committee (registration number WHO 3483).

Patients were administered everolimus after they had progressed mostly on sunitinib, and in some cases on sorafenib or pazopanib therapy. Histological and staging examinations, such as abdominal and chest CT (if clinically indicated, bone scintigraphy and skull CT) were performed before initiating the therapy. $71 \%$ of the patients had a comorbidity that required treatment.

Everolimus Therapy Everolimus $10 \mathrm{mg}$ daily was administered orally in continuous 28 -day cycles. A minimum washout period of 4 weeks followed the previously administered antiVEGFR therapy. Treatment was started when patients' general condition was good; they did not suffer from side-effects of the previous therapies, and after stabilization of symptoms caused by new metastases (e.g., cerebral metastasectomy, brain or bone irradiation, anemia control, etc.). Dose reduction
Table 1 Second and third line clinical trials with everolimus in clear cell renal cell cancer

\begin{tabular}{lllllll}
\hline Trial, Author & Phase & N & Arms & mPFS (months) & ORR (\%) & mOS (months) \\
\hline RECORD-1 & III & \multirow{2}{*}{416} & EVE & 4.9 & 2 & 14.8 \\
Motzer et al. [4, 8] & & & PBO & 1.9 & 0 & 14.4 (crossover) \\
CheckMate 025 & \multirow{2}{*}{ III } & \multirow{2}{*}{821} & NIVO & 4.6 & 25 & 25.0 \\
Motzer et al. [13] & \multirow{2}{*}{ III } & \multirow{2}{*}{658} & EVE & 4.4 & 5 & 19.6 \\
METEOR & \multirow{2}{*}{ CABO } & 7.4 & 17 & 21.4 \\
Choueiri et al. [14, 15] & \multirow{2}{*}{151} & EVE & 3.9 & 3 & 16.5 \\
Motzer et al. [16] & II & \multirow{2}{*}{ LEN + EVE } & 14.6 & 43 & 25.5 \\
& & & LEN & 7.4 & 27 & 18.4 \\
& & & EVE & 5.5 & 6 & 17.5 \\
\hline
\end{tabular}

$C A B O$ cabozantinib, $E V E$ everolimus, $L E N$ lenvatinib, $m O S$ median overall survival, $m P F S$ median progression free survival, $N I V O$ nivolumab, $O R R$ overall response rate, $P B O$ placebo 
or delay was performed according to the Summary of Product Characteristics [1]. Physical examination and laboratory tests were performed every 4 to 8 weeks. Imaging examinations were performed 8 weeks after the initiation of everolimus therapy, and once every twelve weeks thereafter, as indicated by the National Health Insurance. Tumor response was evaluated every 12 weeks according to RECIST 1.0 [18]. Severity of AEs was evaluated based on the National Cancer Institute Common Terminology Criteria for Adverse Events, Version 3.0 (88\% in case of 145 patients) [19]. The patients' general condition was assessed according to ECOG scale [20]. After progression on everolimus, treatment in clinical studies, therapy with interferon, progesterone derivatives, and best supportive care were available as therapeutic options. Our data were collected retrospectively.

Statistical Analysis Statistical analyses were performed by using SPSS 20.0 for Windows (SPSS Inc., Chicago, IL, USA). The association between PFS, OS and age was analyzed using COX regression. The influence of other therapy-related factors (duration of TKI therapy and the time that elapsed between the cessation of TKI therapy and the initiation of everolimus), and patient-related factors (gender, type of previous therapy, ECOG status, and anemia) on PFS and OS was analyzed with Kaplan-Meier analysis.

\section{Results}

Patient Characteristics Out of the 165 patients who participated in the study, $76.4 \%$ were men and $23.6 \%$ were women [Table 2]. The mean age was 63.2 (range, 28-79) years, and $93.9 \%$ of patients had undergone nephrectomy. The general condition of the patients was good with $27.9 \%$ and $63.6 \%$ of patients having ECOG scores of 0 and 1, respectively; $6.1 \%$ and $2.1 \%$ of patients had ECOG scores of 2 and 3, respectively. Common comorbidities were hypertension, other cardiovascular disorders, and diabetes.

Table 2 Patient characteristics

\begin{tabular}{|c|c|c|c|}
\hline & & $\begin{array}{l}\text { Patients } \\
\mathrm{N}=16\end{array}$ & \\
\hline Mean ag & & $63.2 \pm 0$ & \\
\hline Age rang & & $28-79$ & \\
\hline & & $\mathrm{n}$ & $\%$ \\
\hline Gender & Male & 126 & 76.4 \\
\hline & Female & 39 & 22.6 \\
\hline ECOG & 0 & 46 & 27.9 \\
\hline & 1 & 105 & 63.6 \\
\hline & 2 & 10 & 6.1 \\
\hline & 3 & 4 & 2.1 \\
\hline Comorbi & & $\mathrm{n}$ & $\%$ \\
\hline Hyper & & 66 & 40.0 \\
\hline Other & & 16 & 9.7 \\
\hline Diabe & & 18 & 10.9 \\
\hline Secon & & 13 & 7.9. \\
\hline Hema & & 4 & 2.4 \\
\hline Asthm & & 4 & 2.4 \\
\hline Psoria & & 3 & 1.8 \\
\hline Metastas & & & \\
\hline Mean nu & & $2.4(1-6$ & \\
\hline Location & & $\mathrm{n}$ & $\%$ \\
\hline Lung & & 142 & 86.0 \\
\hline Bone & & 67 & 40.6 \\
\hline Distan & & 60 & 36.4 \\
\hline Liver & & 31 & 18.8 \\
\hline Brain & & 21 & 12.7 \\
\hline Supra & & 15 & 9.1 \\
\hline Other & relapse, contralateral kidney, thyroid gland) & - & $<8$ \\
\hline Histopat & & $\mathrm{n}$ & $\%$ \\
\hline Purely & & 146 & 88.5 \\
\hline $\operatorname{ccRCC}$ & & 9 & 5.45 \\
\hline $\mathrm{ccRCC}$ & oth morphology & $2 / 2 / 2$ & $1.2 / 1.2 / 1.2$ \\
\hline $\mathrm{ccRCC}$ & omophobe- / or both morphology & $1 / 1 / 1$ & $0.6 / 0.6 / 0.6$ \\
\hline $\mathrm{ccRC}$ & & 1 & 0.6 \\
\hline
\end{tabular}

ECOG Eastern Cooperative Oncology Group, $n$ number of involved patients, $N$ number of analyzed patients, $c c R C C$ clear cell renal cell cancer, $S E$ standard error 
The mean number of metastatic sites was 2.4 (range, 1-6), and the most common sites of metastasis were the lungs, bones, distant lymph nodes and the liver. The histological type of the tumors was mainly clear cell renal cell cancer (ccRCC) in case of all patients, in most cases pure ccRCC. No rare variants could be detected, only sarcomatoid, papillary, chromophobe or collecting duct morphologies and transformations in the ccRCC were present [Table 2].

No genetic analyses were performed to prove the familial origin of the renal cancer. Renal cancer has developed in 11 $(7.27 \%)$ and in $3(1.8 \%)$ patients under 50 and 40 years of age, respectively. In these cases, there was no information about any benign tumor, paraganglioma, pheochromocytoma or bilateral tumor. Familial origin and multifocality could be observed in 1 and 2 cases, respectively. Bilateral renal cancer and secondary malignancy ( 3 rectal cancers, 2 CLLs, 1 breast cancer) could be detected in 5 and 6 cases, respectively.

Previous Therapies After undergoing nephrectomy, 9.1\% of the patients received adjuvant INF treatment, and $4.8 \%$ of patients received IFN before the administration of VEGFRtargeted therapy. Before receiving everolimus, 93.9\%, 4.8\%, and $1.2 \%$ of patients were given sunitinib, sorafenib, and pazopanib, respectively. The mean $( \pm \mathrm{SE})$ duration of TKI therapy was $11.7( \pm 0.9)$ months. The duration of TKI was $<3$ months in $15.7 \%$ of patients, who were defined as being resistant to primary TKI therapy [21]. The mean $( \pm \mathrm{SE})$ duration between the end of TKI therapy and the beginning of everolimus was $97.7( \pm 10.1)$ days (period between TKIEVE) [Table 3].
Dose Parameters Overall, $6.2 \%$ of the patients required a dose reduction to manage pneumonitis $(4.1 \%)$, grade 2 skin problems $(1.4 \%)$, and face and neck edema $(0.7 \%)$. Furthermore, $8.9 \%$ of the patients required a dose delay with a mean duration of 24 (range, 5-75) days. The reasons for delaying the dose for $>7$ days were cardiovascular symptoms, elevation of renal functions that required dialysis (10 days each), grade 3 diarrhea (9-14 days), cerebral metastasectomy (20 days), and pneumonitis in 2 cases (28 and 30 days).

Efficacy At the time of the analysis, 26.2\% of the patients were being treated, and $53.8 \%$ of the patients were alive. Partial regression, stable disease, and progression occurred in $12.9 \%, 60.7 \%$ and $26.4 \%$ of the patients, respectively. No patients experienced complete regression (CR). The objective tumor response was $12.9 \%$, and the clinical benefit rate was $73.6 \%$ (partial regression + stable disease). The median PFS at a median follow-up time of 21.2 months (95\% CI 7.05-31.45) was 5.4 months (95\%CI 3.83-6.97). The median overall survival time (OS) (based on data from 145 patients) was 16.2 months (95\% CI 12.95-19.45).

AEs The most common AEs were exanthema (25\%), peripheral edema (19\%), stomatitis (19\%), pneumonitis (13\%), nausea, weight loss, fatigue (11\% each), diarrhea (10\%), dyspnea $(10 \%)$, and mucositis (9\%). The most common abnormalities identified in laboratory findings were anemia $(72 \%)$, and elevation in renal function (45\%), liver function (25\%), blood glucose (51\%), cholesterol (44\%) and lipids (35\%). AEs compared with data from the phase III study are presented in Table 4. No severe or life threatening AEs occurred.
Table 3 Previous therapies before everolimus treatment

\begin{tabular}{lll}
\hline & Patients & \\
& $\mathrm{N}=165$ & $\%$ \\
\cline { 2 - 3 } Previous therapies & $\mathrm{n}$ & 93.9 \\
\hline Nephrectomy & 155 & 13.3 \\
Adjuvant IFN & 22 & 12.7 \\
First line IFN before VEGFR-TKI & 21 & 93.9 \\
Sunitinib & 155 & 4.8 \\
Sorafenib & 8 & 1.2 \\
Pazopanib & 2 & 95.1 \\
First line VEGFR-TKI & 157 & 4.8 \\
Second line VEGFR-TKI after IFN & 8 & \\
Duration of previous therapy & & 15.7 \\
Mean duration of VEGFR-TKI, months $( \pm$ SE) & $11.7( \pm 0.9)$ & \\
Duration of VEGFR-TKI $<3$ months, $(\%)$ & 26 & $97.7( \pm 10.1)$ \\
Mean duration between VEGFR-TKI and EVE, days $( \pm$ SE) & & \\
\hline
\end{tabular}

$E V E$ everolimus, $I F N$ interferon- $\alpha, n$ number of involved patients, $N$ number of analyzed patients, $S E$ standard error, TKI tyrosine kinase inhibitor, VEGFR vascular endothelial growth factor receptor 
Table 4 Adverse events of patients who received everolimus

\begin{tabular}{|c|c|c|c|c|c|}
\hline \multirow[t]{3}{*}{ Most common adverse events } & \multicolumn{3}{|c|}{ Hungarian analysis } & \multicolumn{2}{|c|}{ RECORD-1 Registration study [4] } \\
\hline & \multicolumn{3}{|l|}{$n=145$} & \multicolumn{2}{|l|}{$n=269$} \\
\hline & All grade $\%$ & Grade $2 \%$ & Grade $3 \%$ & All grade $\%$ & Grade $3 / 4 \%$ \\
\hline Exanthema (rash) & 25 & 5 & 1 & 29 & $1 / 0$ \\
\hline Peripheral edema & 20 & - & 1 & 25 & $<1 / 0$ \\
\hline Stomatitis & 24 & 2 & - & 44 & $4 /<1$ \\
\hline Weight loss (asthenia) & 17 & 1 & - & 33 & $3 /<1$ \\
\hline Fatigue/ Weakness & 21 & - & - & 31 & $5 / 0$ \\
\hline Diarrhea & 13 & 2 & - & 31 & $1 / 0$ \\
\hline Nausea & 15 & - & - & 26 & $1 / 0$ \\
\hline Mucositis & 13 & 2 & - & 19 & $1 / 0$ \\
\hline Dyspnea & 12 & - & - & 24 & $6 / 1$ \\
\hline Pneumonitis & 11 & 2 & 1 & 14 & $4 / 0$ \\
\hline Decreased hemoglobin & 73 & 21 & 6 & 91 & $9 /<1$ \\
\hline Elevated creatinine & 43 & 5 & 1 & 46 & $<1 / 0$ \\
\hline Elevated liver transaminases & 21 & 4 & 1 & $25-21$ & $0-1$ \\
\hline Elevated glucose level & 53 & 6 & - & 50 & $12 / 0$ \\
\hline Elevated cholesterol & 45 & 3 & - & 76 & $3 / 0$ \\
\hline Elevated lipid & 37 & 4 & - & 71 & $<1 / 0$ \\
\hline Hypothyroidism/ hyperthyroidism & $<1 /<1$ & - & - & - & - \\
\hline
\end{tabular}

$n$ number of analyzed patients

Factors Influencing Efficacy PFS and OS with everolimus were not influenced by the patients' gender, age, the number and type of metastatic organ systems, the presence of the metastasis only in the lungs, the length and type of the previous TKI therapy, or the time between the cessation of TKI treatment and initiating everolimus.
Patients without lung metastasis showed favorable outcome (PFS 5.3 vs 9.1 months $p=0.042$, OS 10.3 vs 15.9 months $p=0.006$ ) [Table 5].

Median PFS and OS of patients treated with TKI therapy $\leq 3$ months, vs $>3$ months were 3.0 vs 5.2 months and 16.0 vs 19.9 months, respectively; however, the differences were not

Table 5 Factors influencing the outcome of everolimus therapy

\begin{tabular}{|c|c|c|c|c|c|}
\hline \multicolumn{2}{|l|}{ Specifications } & \multirow{2}{*}{$\frac{\mathrm{PFS} \pm \mathrm{SE} \text { (months) }}{5.3 \pm 0.7 / 6.4 \pm 1.7}$} & \multirow{2}{*}{$\frac{p \text {-value }}{0.929}$} & \multirow{2}{*}{$\frac{\mathrm{OS} \pm \mathrm{SE} \text { (months) }}{19.9 \pm 3.5 / 18.2 \pm 2.7}$} & \multirow{2}{*}{$\frac{p \text {-value }}{0.544}$} \\
\hline Gender & Man/Woman & & & & \\
\hline Number of metastatic organs & $1 /$ More & $5.3 \pm 1.5 / 5.5 \pm 1.0$ & 0.660 & $18.0 \pm 1.9 / 16.6 \pm 3.2$ & 0.186 \\
\hline Only lung met. / Other met. & & $4.2 \pm 0.5 / 6.4 \pm 0.9$ & 0.116 & $15.5 \pm 3.1 / 21.9 \pm 6.6$ & 0.916 \\
\hline Presence / Lack of lung met. & & $5.3 \pm 0.6 / 9.1 \pm 2.8$ & 0.042 & $10.3 \pm 1.1 / 15.9 \pm 4.7$ & 0.006 \\
\hline ECOG status & $0-1 / 2-3$ & $6.4 \pm 1.1 / 3.5 \pm 0.2$ & 0.033 & $19.9 \pm 6.7 / 7.5 \pm 0.6$ & 0.008 \\
\hline \multirow[t]{3}{*}{ Duration of TKI therapy (months) } & $\leq 3 />3$ & $3.4 \pm 0.6 / 5.9 \pm 0.8$ & 0.250 & $16.0 \pm 4.5 / 19.9 \pm 5.9$ & 0.244 \\
\hline & $\leq 6 />6$ & $4.7 \pm 0.8 / 6.4 \pm 1.3$ & 0.090 & $21.9 \pm 7.2 / 16.6 \pm 2.4$ & 0.840 \\
\hline & $\leq 9 />9$ & $4.5 \pm 0.8 / 7.2 \pm 1.5$ & 0.019 & $16.0 \pm 2.8 / 41.2 \pm 18.6$ & 0.045 \\
\hline Type of TKI & $\mathrm{SU} / \mathrm{SO} / \mathrm{PA}$ & $5.5 / 6.9 / 2.8$ & 0.140 & $18 / 19.9 / 30.9$ & 0.690 \\
\hline \multirow[t]{2}{*}{ Period between TKI-EVE (days) } & $\leq 30 />30$ & $6.5 \pm 0.9 / 5.3 \pm 0.9$ & 0.774 & $11.5 \pm 5.4 / 30.9 \pm 6.8$ & 0.106 \\
\hline & $\leq 60 />60$ & $5.6 \pm 0.6 / 4.5 \pm 1.3$ & 0.601 & $19.9 \pm 4.9 / 16.5 \pm 6.8$ & 0.624 \\
\hline Anemia & G0 / G1-2-3 & $4.8 \pm 1.2 / 6.4 \pm 1.0$ & 0.612 & $30.9 \pm 6.1 / 16.2 \pm 1.4$ & 0.020 \\
\hline PFS (months) & $<12 / \geq 12$ & - & - & $15.5 \pm 1.8 / 41.2 \pm 9.5$ & 0.001 \\
\hline
\end{tabular}

ECOG Eastern Cooperative Oncology Group, EVE everolimus, $G$ grade, met -metastasis, $O S$ median overall survival, $P A$ pazopanib, $P F S$ median progression-free survival, $S E$ standard error, $S O$ sorafenib, $S U$ sunitinib, TKI tyrosine kinase inhibitor

Significant level is: $p<0.05$ 
statistically significant ( $p=0.250$ and $p=0.244$, respectively). PFS and OS were more favorable for patients who received everolimus after receiving TKI therapy for $>9$ months (PFS $p=0.019$, OS $p=0.045$ ) and for patients with an ECOG performance status of 0 or 1 (PFS $p=0.033$, OS $p=0.008$ ).

The presence of anemia predicted a poorer survival rate $(p=0.020)$, while a PFS $>12$ months was a favorable prognostic factor $(p=0.762)$ [Table 5]. Only $25.5 \%$ of the patients received third-line therapy: progesterone derivatives (17.9\%), a TKI in a clinical study (4.1\%), and INF therapy (3.5\%). OS was not significantly different between patients who received these specific third-line therapies and patients who did not receive oncological therapy after everolimus (post EVE therapy) $(p=0.001)$. Examining the effect of ECOG performance status and anemia on survival, the most favorable median OS was observed for patients without anemia and with an ECOG performance status of 0 or $1(30.9 \pm 2.5$ months), whereas it was the most unfavorable median OS observed in patients with anemia and with an ECOG performance status of 2 or 3 (7.7 \pm 4.5 months) $(p=0.029)$. None of other patient or therapy related parameters influenced PFS or OS [Fig. 1].

\section{Discussion}

Modifying the mTOR signal transduction pathway by blocking the proliferation, migration, growing and survival and by indirectly inhibiting VEGF is an important therapeutic strategy of hypervascular RCCs [3]. EVE as an orally administered mTOR serine/threonine kinase inhibitor shows efficiency in secondand third-line therapies of patients with $\mathrm{mRCC}$ after failure of at least one VEGFR-TKI. The safety profile of the drug is favorable. No clear predictive biomarkers are known related to efficacy of EVE. The real world data could confirm results of registration studies and help understand the integration of novel drugs into the daily routine practice.
Values of our retrospective post-registration study with EVE are the multicenter data processing, the high case number in comparison to the population, and the homogeneity of the patients regarding previous therapies.

In our analysis, EVE monotherapy was associated with favorable PFS and OS in patients with $\mathrm{mRCC}$ refractory to previous VEGFR-TKI therapy. Our reported median PFS of 5.3 months is slightly longer than the median PFS of 4.9 months reported in the RECORD-1 registration study [4], and similar to the median PFS of 5.4 months reported in the subgroup of RECORD-1 patients, who had previously received only one line of TKI therapy [9]. The median OS of patients in our study was 16.2 months. In RECORD-1, the median OS was 14.8 in the everolimus arm [8]. Based on the previous details, results of survival data in our study are comparable to the results of the registration study and even the EVE standard arm in recent clinical studies (Checkmate $025 \mathrm{PFS}_{\mathrm{EVE}}$ : 4.4 months, $\mathrm{OS}_{\mathrm{EVE}}$ : 19.6 months), METEOR (PFS EVE $: 3.9$ months, OS EVE 16.5 months), LEN-EVE (PFS $\mathrm{EVVE}_{\mathrm{E}}: 5.5$ months, $\mathrm{OS}_{\mathrm{EVE}}$ : 17.5 months) [13-16] [Table 1].

Regarding PFS, as an indicator of the efficiency of an active agent, results from the everyday practice can be compared with and do not differ significantly from the newly published results. Overall survival data that refer to efficiency of therapeutic sequences based on new results suggest that introducing new therapeutic options positively affect the OS $[4,13,14]$.

In the registration studies and retrospective analyses of EVE, and new active agents (carbozantinib and nivolumab), the safety profiles were homogenous [4, 13, 14, 22].

In our study, the mean duration between ceasing VEGFRTKI treatment and initiating everolimus therapy was 97.7 days. There were several reasons for delaying the start of the administration of everolimus, including resolving AEs associated with VEGFR-TKI therapy to at least to grade 1, stabilizing symptoms caused by new metastases (if necessary cerebral metastasectomy, brain or bone irradiation), patient flow between the institutes, organizing radiological examinations, and drug
Fig. 1 Effect of ECOG status and anemia on overall survival. Kaplan-Meier analysis of OS was compared in patients with anemia and ECOG $2-3$ status

(7.7 \pm 4.5 months) vs the absence of anemia and ECOG $0-1$ status $(30.9 \pm 2.5$ months $)$ vs only one unfavorable prognostic factor is present (16.2 \pm 3.7 months) $(p=0.029)$. (ECOG - Eastern Cooperative Oncology Group, OS - overall survival, SE - standard error)

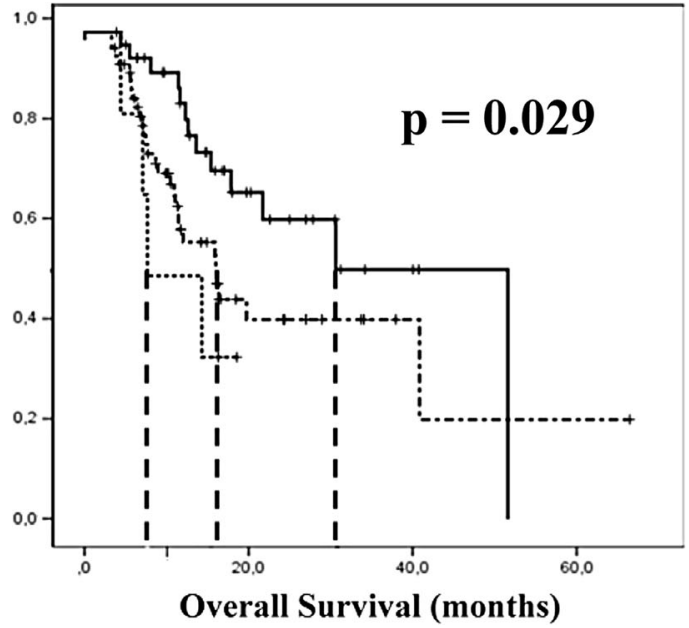

OS \pm SE (months)

ECOG 0-1 without anemia $30.9 \pm 2.5$

ECOG 0-1 with anemia or ECOG 2-3 without anemia -.- 16.2 23.7

ECOG 2-3 with anemia ..... $7.7 \pm 4.5$ 
availability. The length of time between TKI and mTOR inhibitor therapies was similar to the time between ending TKI therapy and beginning everolimus following progression on placebo in the RECORD-1 study. Surprisingly, despite the length of time between TKI-EVE, we could not have proven any unambiguous, negative effect of it in our population.

We also investigated parameters that could influence the efficacy of everolimus.

Patients' favorable general condition (ECOG 0-1) was associated with a longer PFS and OS. The lack of anemia was associated with longer survival. After the introduction of new, registered therapeutic options, analysis of these prognostic factors might be useful during the evaluation of early experience.

We did not find a correlation between patients' other general characteristics, the type of previous TKI therapy or and its therapeutic outcome. We also evaluated the effect of primary resistance to VEGFR-TKI therapy on subsequent everolimus efficacy. Although differences were not statistically significant, PFS and OS tended to be less favorable in patients who experienced primary TKI resistance. Similar results have been reported in international studies [23]. Similarly to our results, Bergmann et al. found no correlation between the type or duration ( $<$ or $>3$ or 6 months) of previous TKI therapy and the efficacy of everolimus in VEGF-refractory patients with mRCC [24]. In our study, we found that patients whose VEGFR-TKI therapy was $>9$ months had significantly more favorable PFS and OS [24].

The prognostic score system published by Motzer for second-line therapy demonstrated unfavorable prognosis in the presence of 3 factors: anemia, poor general health (Karnofsky performance status $<80$ ), and a high level of corrected calcium $(>10 \mathrm{mg} / \mathrm{dL}$ or $>2.4 \mathrm{mmol} / \mathrm{L})$, instead of the 5 factors used to determine prognosis for first-line therapy [25]. In our population, we demonstrated that poor general health negatively influenced survival. If the patients' general condition was good, and they did not have anemia, the OS was 30.9 months, but if they had poor health and anemia, OS time decreased to 7.7 months. In our analysis, we found that ECOG performance status was one of the most important factors that affect PFS. OS was remarkably better in patients with a duration of everolimus therapy $>12$ months. This underlines the importance of appropriate patient selection. After longer duration of everolimus therapy, the number of third-line therapies decreased without influencing survival, so the properly selected, effective second-line therapy determined the patients' life expectancy.

Conclusions mTOR inhibition is an effective way to treat patients with VEGFR-TKI refractory mRCC. According to experience in the Hungarian everyday practice, VEGFR-TKI refractory patients in good general health, having adequate hematological values, and $>9$ months of previous VEGFRTKI therapy may experience delayed disease progression and improved survival while maintaining good quality of life during the second-line everolimus therapy. Despite the more favorable efficiency of new, registered drugs, EVE therapy still plays role during and after second-line therapy for $\mathrm{mRCC}$ in regions where modern remedies are only limitedly available, they have not been introduced yet, or their administration is contraindicated due to medical reasons.

Acknowledgments We express our thanks to the doctors for their work and for the data they made available for this study: Csilla András, Krisztina Bíró, Anita Bokor, Zsófia Dankovics, Gergely Dombóvári, Andrea Gonda, Fruzsina Gyergyai, Attila Huszár, Balázs Juhász, Erika Kövér, Zsófia Küronya, Zsuzsanna Miszlai, Krisztián Nagyiványi, Hajnalka Németh, Ágota Petrányi, Tibor Solymosi, Éva Szilágyi, Éva Szekanecz, Judit Tóth, Miklós Wenczl and Judit Zsálek, and all members of their institutes who contributed to this study.

\section{Compliance with Ethical Standards}

Conflict of Interest Anikó Maráz has received honoraria from Bayer, Bristol-Myers Squibb, and has served on advisory boards for Novartis. András Csejtei has served on advisory boards for Novartis and Pfizer. Judit Kocsis has received honoraria from Bayer and served as a member of advisory board: Novartis, Bristol-Myers Squibb and Pfizer. Miklós Szűcs has received honoraria from Bayer, Novartis, BristolMyers Squibb and has served on advisory boards for Novartis and Pfizer. Zsuzsanna Kahán has no actual or potential conflicts of interest to report. György Bodoky has received honoraria from Bayer, Bristol-Myers Squibb and Pfizer and has served on advisory boards for Novartis and Pfizer. Magdolna Dank has received honoraria from Bayer, Novartis and Pfizer and has served on advisory boards for Novartis and Pfizer.

László Mangel has received honoraria from Pfizer and has served on advisory boards for Novartis and Pfizer.

János Révész has served on advisory boards for Novartis and Pfizer. Zoltán Varga has no actual or potential conflicts of interest to report. Lajos Géczi has received honoraria from Bayer, Novartis, BristolMyers Squibb and Pfizer and has served on advisory boards for BristolMyers Squibb, Novartis and Pfizer.

Ethical Approval All procedures performed in the studies involving human participants were in accordance with the ethical standards of the institutional and/or national research committee and with the 1964 Helsinki Declaration and its later amendments or comparable ethical standards. For this type of study no formal consent is required.

Support This was a non-sponsored study.

\section{References}

1. Afinitor EMEA Summary of Product Characteristics: http://www. ema.europa.eu/docs/hu_HU/document library/EPAR - Product Information/human/001038/WC500022814.pdf

2. Hay N, Sonenberg N (2004) Upstream and downstream of mTOR. Genes Dev 18:1926-1945

3. Eisen HJ, Tuzcu M, Dorent R et al (2003) Everolimus for the prevention of allograft rejection and vasculopathy in cardiactransplant patients. N Engl J Med 349:847-858

4. Motzer RJ, Escudier B, Oudard S et al (2008) Efficacy of everolimus in advanced renal cell carcinoma: a double-blind, randomised, placebo-controlled phase III trial. Lancet 372:449-456 
5. Yao JC, Shah MH, Ito T et al (2011) Everolimus for Advanced Pancreatic Neuroendocrine Tumors. N Engl J Med 364:514-523

6. Yao JC, Fazio N, Singh S et al (2016) Everolimus for the treatment of advanced, non-functional neuroendocrine tumours of the lung or gastrointestinal tract (RADIANT-4): a randomised, placebo-controlled, phase 3 study. Lancet 387:968-977

7. Baselga J, Campone M, Piccart M et al (2012) Everolimus in postmenopausal hormone-receptor-positive advanced breast cancer. $\mathrm{N}$ Engl J Med 366:520-529

8. Motzer RJ, Escudier B, Oudard S et al (2010) Phase 3 trial of everolimus for metastatic renal cell carcinoma: final results and analysis of prognostic factors. Cancer 116:4256-4265

9. Calvo E, Escudier B, Motzer RJ et al (2011) Everolimus in metastatic renal cell carcinoma: subgroup analysis of patients with 1 or 2 previous vascular endothelial growth factor receptor-tyrosine kinase inhibitor therapies enrolled in the phase III RECORD-1 study. Eur J Cancer 48:333-339

10. NCCN Guideline. https://www.nccn.org/professionals/physician gls/pdf/kidney.pdf

11. Escudier B, Porta C, Schmidinger M et al (2014) Renal cell carcinoma: ESMO Clinical Practice Guidelines for diagnosis, treatment and follow-up. Ann Oncol 25:49-56

12. Ljungberg B, Bensalah $\mathrm{K}$, Canfield $\mathrm{S}$ et al (2015) EAU Guidelines on Renal Cell Carcinoma: 2014 Update. Eur Urol 67:913-924

13. Motzer RJ, Escudier B, McDermott DF, el al (2015) Nivolumab versus Everolimus in Advanced Renal-Cell Carcinoma. N Engl J Med 373:1803-1813

14. Choueiri TK, Escudier B, Powles T et al (2015) Cabozantinib versus Everolimus in Advanced Renal-Cell Carcinoma. N Engl J Med 373:1814-1823

15. Choueiri TK, Escudier B, Powles T et al (2016) Cabozantinib versus everolimus in advanced renal cell carcinoma (METEOR): final results from a randomised, open-label, phase 3 trial. Lancet Oncol 17:917-927
16. Motzer RJ, Hutson TE, Glen H et al (2015) Lenvatinib, everolimus, and the combination in patients with metastatic renal cell carcinoma: a randomized, phase 2, open-label, multicenter trial. Lancet Oncol 16:1473-1482

17. Escudier B, Porta C, Schmidinger M et al (2016) Renal Cell Carcinoma: ESMO Clinical Practice Guidelines. Ann Oncol 27: $58-68$

18. Therasse P, Arbuck SG, Eisenhauer EA et al (2000) New guidelines to evaluate the response to treatment in solid tumors. J Natl Cancer Inst 92:205-214

19. Common Terminology Criteria for Adverse Events, version 3.0 issued by National Cancer Institute EORTC, 09. 08 (2006) http:// ctep.cancer.gov/protocolDevelopment/electronic_applications/ docs/ctcaev3.pdf

20. ECOG performance status. http://ecog.dfci.harvard.edu/general/ perf_stat.html

21. Rini BI, Flaherty K (2008) Clinical effect and future considerations for molecularly-targeted therapy in renal cancer. Uro Oncol Semin Orig Investig 26:543-549

22. Grünwald V, Karakiewicz PI, Bavbek SE et al (2012) An international expanded-access programme of everolimus: addressing safety and efficacy in patients with metastatic renal cell carcinoma who progress after initial vascular endothelial growth factor receptortyrosine kinase inhibitor therapy. Eur J Cancer 48:324-332

23. Calvo E, Ravaud A, Bellmunt J (2013) What is the optimal therapy for patients with metastatic renal cell carcinoma who progress on an initial VEGFr-TKI? Cancer Treat. Rev. 39:366-374

24. Bergmann L, Kube U, Doehn C et al (2015) Everolimus in metastatic renal cell carcinoma after failure of initial anti-VEGF therapy: final results of a noninterventional study. BMC Cancer 15:303

25. Motzer RJ, Bacik J, Schwartz LH et al (2004) Prognostic factors for survival in previously treated patients with metastatic renal cell carcinoma. J Clin Oncol 22:454-463 